\title{
Prioritising the cardiac surgery waiting list: the angina patient's perspective
}

\author{
Frank Kee, Penny McDonald, Brian Gaffney
}

\begin{abstract}
Objective-To determine patients' views on how clinical and demographic factors should affect priorities for cardiac revascularisation.

Design-A descriptive survey of patients' views conducted immediately after angiography and treatment counselling.

Subjects-136 patients who were awaiting coronary angioplasty in either of the two regional cardiology centres in Northern Ireland.

Results-About half the subjects (52\%) felt that certain social factors such as having dependent relatives should be taken into account when deciding priority for surgery. A sizeable minority felt that younger subjects and non-smokers (40\% and $44 \%$, respectively) should be accorded higher priority, with older subjects and smokers being more likely to hold such views.

Conclusions-While there is little evidence that demographic and lifestyle factors affect the relative efficacy of surgery, the challenge remains to devise a prioritisation guideline that can properly reflect societal values and the evidence base.
\end{abstract}

(Heart 1997;77:330-332)

Keywords: revascularisation; prioritisation; patients' views

Department of

Epidemiology and

Qublic Health, The

Belfast, Northern

Ireland

F Kee

Department of Public

Health Medicine,

Northern Health and

Social Services Board

$\mathrm{P}$ McDonald

Department of Public

Health Medicine,

Eastern Health and

Social Services Board

B Gaffney

Correspondence to:

Dr Frank Kee, Department

of Epidemiology and Public

of Epidemiology and

Health, The Queen's

Mulhouse, Royal Victoria

Mulhouse, Royal Victoria Belfast BT12 6BJ, Northern
Ireland.

Accepted for publication

16 December 1996
In the past few years there has been a vigorous debate on how patients should be prioritised for cardiac surgery. ${ }^{1-4}$ The need for greater clarity in this regard has recently been emphasised both by the Clinical Standards Advisory Group $^{5}$ and by the Audit Commission. ${ }^{6}$ Establishing a set of agreed principles or ground rules might not only assist surgeons to resist criticism of a "black box" approach, but should help general practitioners and patients to understand better how the system operates and alleviate some of the anxiety which, for many patients, overshadows anginal pain as the most troublesome symptom experienced while awaiting surgery. ${ }^{7}$ Among the clinical indications for bypass surgery, the objectives can be either to reduce mortality risk or to alleviate symptoms but it is remarkable how many general practitioners believe that the vast majority of patients awaiting surgery will have their lives extended by revascularisation. ${ }^{8}$ Given the limited consultation time a patient might have with the surgeon in the outpatient department, this misplaced optimism is often implicitly transmitted to the patient, who then feels at risk of dying for want of the operation, rather than, if anything, from the natural history of the condition. Communication between patients and doctors clearly needs to be improved. Indeed, a case might be made for involving patients themselves in establishing the ground rules for prioritisation, as many of the arguments have no "scientific" answer and are highly value laden. ${ }^{1-4}$

We have surveyed patients awaiting angioplasty to ascertain the importance they ascribe to certain clinical and demographic characteristics which have been the focus of recent debate on prioritisation. Before we started our study, there had been wide speculation in the local press about health services rationing, on the heels of a report by the chief medical officer about cardiac surgery waiting times. There was some debate in the press about the "plight" of patients who smoked or who were overweight and there was a public perception that such patients would be disadvantaged and would not receive the same priority as non-smoking or lean subjects. Since our study questions might have only served to add to the anxiety of some patients on the cardiac surgery waiting list (who might fear that their answers could prejudice their own position), we chose instead to obtain the views of patients who had just had angiography and were joining the waiting list for coronary angioplasty. In every such case the potential future need for cardiac surgery is explained by the cardiologist. However, we felt that our questions could be answered by patients who were one step removed from the actual surgical waiting list without causing them any anxiety that we were in some way "policing" their lifestyle.

One of the key issues surrounding the growing fashion for citizens' juries deliberating on the rationing of health care is the question of whose views should inform the debate. Obviously, any individual group, whether "experts", managers, or patients who will be directly affected by allocating decisions, may articulate their own perspective biased towards their own needs and values. The crucial issue for any "jury", therefore, is to establish the appropriate weighting to apply to the values of the various groups. ${ }^{9} \mathrm{We}$ have made a first attempt to sample the views of one group of stakeholders in this debatepatients with coronary artery disease who have been counselled about the effects of their disease and about various treatment options. 


\section{Methods}

As part of a larger study on patients' perceptions of coronary angioplasty, 136 patients were asked to give their views on the prioritisation process for revascularisation. A copy of the relevant section of the questionnaire is shown in the appendix. Patients were recruited consecutively from both of the regional cardiology centres in Northern Ireland and interviews were usually conducted on the same day as the initial angiography, but after the consultant cardiologist in charge had counselled the patient about treatment options. The questionnaire had undergone a pilot development phase by two experienced research nurses who conducted all of the interviews. Patients were recruited consecutively between February and October 1995.

Patients were asked to rate their own urgency for intervention by responding to two separate visual analogue scales, one reflecting their own current state of health and the other what they anticipated might be their state of health if they were not to receive their treatment for six months. Their perception of urgency was rated by subtracting the two.

In the analysis, patients were categorised into groups according to demographic and clinical factors, and according to how urgent they perceived their own case to be. Comparisons were made between groups using the $\chi^{2}$ statistic for contingency tables. Adjustment for other variables was performed, after stratification, by the Mantel-Haenszel method.

Table 1 Priority for cardiac surgery: patients' perspective

\begin{tabular}{llcl}
\hline & $\begin{array}{l}\text { Increased priority } \\
\%(n)\end{array}$ & $\begin{array}{l}\text { Decreased priority } \\
\%(n)\end{array}$ & $\begin{array}{l}\text { No difference } \\
\%(n)\end{array}$ \\
\hline Young ( $v$ older subjects) & $40(54)$ & $2(3)$ & $58(79)$ \\
Male $(v$ female) & $7(9)$ & $0 \cdot 7(1)$ & $92(126)$ \\
Obese $(v$ non-obese) & $14(19)$ & $23(32)$ & $63(85)$ \\
Smokers $(v$ non-smokers) & $17(23)$ & $44(60)$ & $39(53)$ \\
Employed $(v$ unemployed) & $27(37)$ & $0 \cdot 7(1)$ & $72(98)$ \\
Dependents $(v$ those without) & $52(71)$ & $0(0)$ & $48(65)$ \\
Severe symptoms ( $v$ less severe) & $93(127)$ & $1.5(2)$ & $5(7)$ \\
\hline
\end{tabular}

Table 2 Priority for cardiac surgery: patients' perspective, age

\begin{tabular}{llll}
\hline & $\begin{array}{l}\text { Increased priority } \\
\text { accorded to } \\
\text { younger patients } \\
\%(n)\end{array}$ & $\begin{array}{l}\text { Increased priority } \\
\text { accorded to } \\
\text { older patients or } \\
\text { indifferent to age } \\
\%(n)\end{array}$ & \\
\hline $\begin{array}{l}\text { Young patients } \\
\begin{array}{l}\text { O8 years and under) } \\
\text { Older patients } \\
\text { (above 58 years) }\end{array}\end{array}$ & $31(21)$ & $69(46)$ & $100(67)$ \\
\hline$\chi^{2}=4 \cdot 23, \mathrm{df}=1, \mathrm{P}=0.039$. & $51(36)$ & $100(70)$ \\
\hline
\end{tabular}

Table 3 Priority for cardiac surgery: patients' perspective, smoking

\begin{tabular}{llll} 
& $\begin{array}{l}\text { Increased priority } \\
\text { accorded to } \\
\text { smokers } \\
\%(n)\end{array}$ & $\begin{array}{l}\text { Increased priority } \\
\text { accorded to non-smokers } \\
\text { or indifferent to } \\
\text { smoking habit } \\
\%(n)\end{array}$ \\
\hline $\begin{array}{l}\text { Non-smoker } \\
\text { Smoker }\end{array}$ & $22(22)$ & $78(80)$ & $100(102)$ \\
\hline
\end{tabular}

$\chi^{2}=6.53, \mathrm{df}=1, \mathrm{P}=0.011$
Results

Table 1 summarises the results according to whether the participants considered that particular sorts of otherwise clinically comparable patients deserved a higher or lower priority on a revascularisation waiting list. A majority of subjects felt that patients with dependent relatives should be accorded higher priority and a significant minority felt that increased priority should be given to non-smokers and to young patients. Almost a quarter of subjects felt that lower priority should be given to obese patients.

It was the older subjects (above the sample's median age) who were more likely than their younger counterparts to give higher priority to young patients (table 2). Similarly, it was the smokers who were more likely (than nonsmokers) to accord higher priority for surgery to non-smoking patients (table 3). There were no significant differences in prioritisation criteria between patients according to how urgent they deemed their own case to be.

\section{Discussion}

We have documented the views of some of the major stakeholders in the prioritisation process who, until now, have seldom informed the debate. ${ }^{1-4}$ We felt that by choosing to study patients having angioplasty for angina, we could obtain views that were relatively uncontaminated by any immediate fear of major surgery or apprehension that their responses, particularly in regard to lifestyle habits, might prejudice their care. Nevertheless the patients had all been counselled about the possible future need for surgical revascularisation if angioplasty failed.

In common with a substantial number of Northern Ireland general practitioners, ${ }^{10}$ a majority of patients was inclined to suggest that non-smokers, younger patients, and those with dependants should be given priority in the queue for cardiac surgery. While most were neutral towards factors such as the patients' sex, a sizeable minority felt that unemployed patients and the obese should be accorded a lower priority.

In open questioning, patients were given the option to comment on or justify their views. Many were able to articulate a clear rationale. For example, those who thought that smokers or older patients should receive priority often thought that it was right to offer surgery to those with the highest risks of death. On the other hand, as was more frequently the case, those who thought that younger patients or those with dependants deserved priority often said that such people had more "to offer" society or "had their life ahead of them". Though we were surprised at the apparently public spirited attitude of some who, according to their own criteria, might be displaced in the queue for surgery (for example, smokers and the older patients), this may or may not reflect the view that they would hold if they thought their need was imminent. However, we found little difference after adjusting for perceived urgency of current need for intervention. The 
clinical spectrum of severity of this group of patients may not be typical of those waiting for cardiac surgery itself. However, the available data suggest that their symptom burden is no less severe. Twenty five per cent had grade I or II angina. The equivalent proportion for a recent random sample of patients on the cardiac surgery waiting list was $49 \% .^{11}$

Our findings might be perceived as shoring up the views of those who would argue for more explicit consideration of societal benefits in medical decision making, perhaps implying a need for constructing a "SQALY" - a social quality adjusted life year (QALY) - in evaluating health service interventions. ${ }^{12}$ However, Harris has argued that the value of life can only sensibly be taken to be that value that those alive place on their lives. ${ }^{13}$ While arguments about "justice" feature prominently in this debate, what for us is more pertinent is the fact that the prioritisation criteria that many of these subjects employed seemed to be based on "capacity to benefit", predicated firstly in regards to averting or delaying mortality. Unfortunately, as we have reported previously, ${ }^{14}$ most of them are misinformed (and vastly optimistic) about the capacity of revascularisation to extend life, like many of their doctors. $^{8}$

One of the hallmarks of a valid clinical guideline, whether for cardiac prioritisation or anything else, is the involvement of all key stakeholders, including patients. While there is actually little evidence that the relative efficacy of surgery, in terms of mortality risk reduction (compared with continued medical treatment), is any different for smokers than for non-smokers, ${ }^{15}$ or for fat than for lean patients ${ }^{16}$ or, within bounds, for young than for old subjects, it is only to be hoped that all parties might bring informed opinion to the debate. A recent consensus conference in Northern Ireland on this subject (which no patients attended) concluded that it was generally inappropriate to take account of demographic or lifestyle factors when making prioritisation decisions for cardiac surgery. Thus in an age of evidence based medicine, the challenge remains to devise a guideline which can reflect and balance both societal values and the evidence base.

1 Underwood MJ, Bailey JS. Controversies in treatment: coronary bypass surgery should not be offered to smokcoronary bypass surgery shoul
ers. $B M \mp 1993 ; 306: 1047-8$.

2 Shiu M. Controversies in treatment: refusing to treat smokers is unethical and a dangerous precedent. $B M \mathcal{F} 1993$ ers is unethical

3 Zolese G. Each patient is a special case. BMF 1993;306: 1408 .

4 Bhattacharya $S$. Higher complication rates not confined to smokers. BMF 1993;306:1409.

5 Coronary artery bypass grafting and coronary angioplasty. Access to and availability of specialist services. Report of CSAG working group. Chaired by Sir Terence English London: HMSO, 1993.

6 Audit Commission. Dear to our hearts. Commissioning services for the treatment and prevention of CHD. London: Audit Commission, 1995.

\section{Appendix}

The questionnaire used in the study

After angioplasty has been performed...before discharge

With whom have you spoken about your treatment since undergoing the procedure?

1 Cardiologist 1 Yes 2 No

$2 \mathrm{SR} / \mathrm{Reg} \quad 1 \mathrm{Yes} 2 \mathrm{No}$

$3 \mathrm{SHO} \quad 1 \mathrm{Yes} 2 \mathrm{No}$

4 Other 1 Yes 2 No

Based on what you have been told, how successful do you feel the treatment has been in clearing the blockage in your coronary artery?

Indicate how successful on a scale of 1 to 5 .

where 5 equals COMPLETE success 4 equals SUBSTANTIAL succes 3 equals MODERATE success 2 equals A LITTLE success

and 1 equals NOT SUCCESSFUL AT ALL

Heart disease is very common in Northern Ireland. This cardiac unit performs hundreds of angioplasties each year and so not every patient can have their treatment immediately.

What factors would you consider it reasonable for cardiologists to take account of, when deciding who should receive relatively higher priority?

There is no right or wrong answer and it is your own views which are important to us.

Apart from the specific factor indicated, consider that the groups being compared are similar in other respects, including disease severity.

(please circle)

$\begin{array}{lll}\text { Increased } & \text { Decreased No } \\ \text { priority } & \text { priority } & \text { differ }\end{array}$

Severity of symptoms

(eg. more severe versus

Gender

(eg. male versus female

patients)

Obesity

(eg. the obese versus non-

obese patients)

Smoking habit

(eg. smokers versus non-

smokers)

Employment status

(eg. breadwinners versus

non-breadwinners)

Number of dependants

(those with dependant childre

versus those without)

Age

(the relatively young versus

older subjects)

If response " 1 " or " 2 " is selected, what age would be
considered the lower limit of the "older" age group?

7 Bengston A, Herlitz J, Karlsson T, Hjalmarson A. Distress correlates with the degress of chest pain: a description of patients awaiting revascularisation. Br Heart $\mathcal{F}$ 1996;75: 257-60

8 Kee F, Gaffney B, Canavan C, Little J, McConnell W, Telford AM, et al. Expanding access to coronary artery bypass surgery:who stands to gain? Br Heart $\mathcal{F} 1995 ; 73$ : 129-33.

9 New B, on behalf of the Rationing Agenda Group. The rationing agenda in the NHS. BMF 1996;312:1593-601.

10 Kee F, Gaffney B, Canavan C, Little J, McConnell W, Telford AM, et al. Having your coronary arteries studied: is choosing your doctor important? Quality in Health Care is choosing your

11 Kee F, Gaffney B. Priority for coronary artery surgery: who gets bypassed when demand outstrips capacity? $Q \mathcal{F} \mathrm{Med}$ 1995;88:15-22.

12 Nord $\mathrm{E}$. The significance of contextual factors in valuing health states. Health Policy 1989;13:189-98

13 Harris J. The value of life. London: Routledge, 1985

14 Kee F, McDonald P, Gaffney B. Coronary angioplasty, the patient's perspective. Paper presented at the conference of the European Society of Public Health, Budapest. December, 1995.

15 Julian D. Smoking and coronary heart disease. Br Heart $\mathcal{f}$ 1994;72:9-11 